\title{
Relationship between stress relaxation behavior and thermal stability of natural rubber vulcanizates
}

\author{
Nabil Hayeemasae ${ }^{1}$ and Abdulhakim Masa* \\ ${ }^{1}$ Department of Rubber Technology and Polymer Science, Faculty of Science and Technology, \\ Prince of Songkla University, Pattani Campus, Pattani, Thailand \\ ${ }^{2}$ Sino-Thai International Rubber College, Prince of Songkla University, Hat Yai, Songkhla, Thailand \\ *abdulhakim.m@psu.ac.th
}

\begin{abstract}
It is well-recognized that different sulphur curing systems have greatly influenced to the final properties of the rubber vulcanizates. In this study, the properties of vulcanizates with conventional vulcanization (CV) and efficiency vulcanization (EV) systems were correlated in the aspect of stress relaxation and thermal stability. The stress relaxation behaviour and thermal stability were studied with the temperature scanning stress relaxation (TSSR) and with thermogravimatric analysis (TGA) techniques, respectively. Thermo-oxidative degradation of rubber chains in the CV system was greater than the EV system, leading to easier stress relaxation and poorer aging resistance of the CV system. Also, thermal stability of the rubber crosslinked with CV system was poorer than that with the EV system as corroborated by the activation energy of degradation. TSSR result correlated well with TGA result, and both revealed type of crosslinkages governed the thermo-oxidative degradation and thermal stability of vulcanizates.
\end{abstract}

Keywords: natural rubber, stress relaxation, thermal stability, crosslink system.

How to cite: Hayeemasae, N., \& Masa, A. (2020). Relationship between stress relaxation behavior and thermal stability of natural rubber vulcanizates. Polímeros: Ciência e Tecnologia, 30(2), e2020016. https://doi.org/10.1590/0104-1428.03120.

\section{Introduction}

It is well known that unvulcanised NR has low strength, is unstable over a wide range of temperatures, and cannot recover its original shape after a large deformation ${ }^{[1,2]}$. Therefore, all typical NR products require vulcanizing. This is a chemical process, converting viscous rubber materials into three-dimensional elastic crosslinked networks by using chemicals and heat ${ }^{[3]}$. As a result, the vulcanizates are less sensitive to heat or cold and have elasticity, strength and stability in the ranges needed in applications ${ }^{[4]}$. By far, sulfur is the most extensively used crosslinking agent in the rubber industries as it is cost-effective, broadly compatible with compounding ingredients, and allows to predict the eventual vulcanizate properties ${ }^{[5]}$. In general, sulfur vulcanization systems are either conventional (CV), semi-efficient (Semi-EV), or efficient (EV) types, and the linkages generated by vulcanization reactions can be either mono- (C-S-C), di- (C-S -C), or polysulfidic (C-S $-\mathrm{C}$; $\mathrm{x}>2$ ) crosslinks, depending on accelerator/sulfur ratio. The $\mathrm{CV}$ systems have accelerator/sulfur ratio below 0.7 ; EV has this ratio above 2.5; and semi-EV is used to label the remaining cases ${ }^{[6,7]}$. It has been proven that the $\mathrm{CV}$ systems give a large proportion of polysulfidic linkages with bond strengths less than $262 \mathrm{~kJ} / \mathrm{mol}$, while EV systems tend to create more monosulfidic linkages with bond strengths of about $280 \mathrm{~kJ} / \mathrm{mol}^{[8,9]}$. Due to the lower bond strength, poorer thermal ageing is typical with the CV system. Several prior studies have assessed the properties of NR with different types of crosslinks. Pimolsiriphol et al. ${ }^{[8]}$ investigated thermal aging degradation of $\mathrm{CV}$ and $\mathrm{EV}$ crosslinked NR, and found that the thermal ageing properties of NR vulcanizates depend strongly on crosslink density. On the other hand, Larpkasemsuk et al. ${ }^{[10]}$ reported that for epoxidized natural rubber the highest tensile strength and oil resistance were obtained with a CV system, but the highest thermal stability was achieved with a semi-EV system due to high crosslink density with thermally comparatively stable mono- and disulfidic linkages. Boonkerd et al. ${ }^{[11]}$ found that adding polysulfidic linkages gave the vulcanizate a higher tensile strength but a lower reversion resistance. Rattanasom et al. ${ }^{[12]}$ also found that NR/tire tread reclaimed rubber blend vulcanizates had better heat aging resistance with an EV system than with $\mathrm{CV}$, due to the better thermal stability of mono- and di-sulfidic crosslinks compared to polysulfidic linkages. Although various studies have reported on mechanical and thermal properties achieved with CV and EV systems but the discussions remained in contradiction.

Temperature scanning stress relaxation (TSSR) measurement is a well-known technique used for determining stress relaxation behaviors of thermoplastic elastomers ${ }^{[13]}$. However, it was also useful for analysing relaxation behaviour or thermo-mechanical behaviour of unfilled rubbers vulcanizates ${ }^{[14-16]}$. Vennemann et al. ${ }^{[14]}$ determined the relaxation behavior of NR crosslinked with different vulcanization systems by using TSSR. They found that the ratio of sulfur to accelerator has a large influence on the 
relaxation behavior of vulcanizates. Furthermore, they also found that the change of stress relaxation behavior was caused by the cleavage of crosslinks or scission of main chains. Similar observation was also noticed by Oncel et al ${ }^{\left[{ }^{[1]}\right]}$ when they studied the oxidative thermal aging behaviour of the NR containing new type of antioxidants. Karaagac et al. ${ }^{[16]}$ used TSSR to investigate the stress relaxation of NR and ethylene propylene diene rubber and revealed the effect of molecular weight on the pattern of stress relaxation. For the same polymer, the higher molecular weight shifted the pattern of stress relaxation to higher temperature. Though there have been reports on the relaxation behaviour of the NR but an attempt to correlate low temperature relaxation behaviour (lower than $300^{\circ} \mathrm{C}$ ) with thermal properties tested are still largely unexplored.

To address this aspect, alternative sulfur vulcanizing systems were used to experimentally assess the effect of vulcanization system on stress relaxation and thermal properties of NR, along with other properties. The aim is to reveal the consistency between relaxation behavior and thermal properties of two different crosslink systems. Unfilled NR is crosslinked with two alternative sulfur vulcanization systems, namely of CV and EV types, with fixed total contents of the crosslinking agent and accelerator, the relation of stress relaxation behavior with thermal degradation resistance is discussed.

\section{Materials and Methods}

\subsection{Materials}

The NR (STR 5L) was purchased from Chalong Concentrated Natural Rubber Latex Industry Co., Ltd., Thailand. Stearic acid and zinc oxide $(\mathrm{ZnO})$ used as activators for the sulfur curing system were manufactured by Imperial Chemical Co. Ltd., Pathumthani, Thailand and Global Chemical Co. Ltd., Samutprakarn, Thailand, respectively. N-cyclohexyl-benzothiazyl-sulphenamide (CBS) purchased from Flexsys America L.P., West Virginia, USA, was used as accelerator, and the sulfur was manufactured by Siam Chemical Co., Ltd., Samut Prakan, Thailand.

\subsection{Sample preparation}

NR was compounded with other ingredients, namely stearic acid, $\mathrm{ZnO}, \mathrm{CBS}$ and sulfur, using an internal mixer (Brabender ${ }^{\circledR} \mathrm{GmbH} \& \mathrm{Co} . \mathrm{KG}$, Duisburg, Germany) at a fixed fill factor of 0.8 , initial temperature of $40^{\circ} \mathrm{C}$ and a rotor speed of $60 \mathrm{rpm}$. The chemical formulations, mixing steps and mixing times are displayed in Table 1. Total ingredient contents were kept constant at 107 part(s) per hundred parts of rubber (phr) while mixing time of all samples was fixed at $5 \mathrm{~min}$. The mixing torque was recorded and the compounds were finally compression molded at $160{ }^{\circ} \mathrm{C}$ using a laboratory hot press according to their respective curing times. In this study, the compound formulation was designed to incorporate only necessary additives in order to minimize undesired properties. Thus, the effect of crosslink types on thermal property can be truly estimated.

\subsection{Characterization}

\subsubsection{Curing characteristics}

The curing characteristics of different NR compounds were measured at $160{ }^{\circ} \mathrm{C}$ for 20 minutes, using a Moving die rheometer, MDR 3000 Basic (Montech, Germany). The rheometric parameters scorch time $\left(\mathrm{T}_{\mathrm{s} 1}\right)$, cure time $\left(T_{c 90}\right)$, maximum torque $\left(\mathrm{M}_{\mathrm{H}}\right)$, torque difference $\left(\mathrm{M}_{\mathrm{H}}-\mathrm{M}_{\mathrm{L}}\right)$ and cure rate index (CRI) were determined. $\mathrm{T}_{\mathrm{c} 90}$ is the time at which $90 \%$ of cure has taken place and can be estimated as:

$$
T_{c 90}=M_{L}+0.9\left(M_{H}-M_{L}\right)
$$

The cure rate indexes (CRIs) for the compounds were calculated from:

$$
C R I=\frac{100}{T_{c 90}-T_{s 1}}
$$

where, $\mathrm{T}_{c 90}$ is the time at $90 \%$ vulcanization ( $\mathrm{min}$ ) and $\mathrm{T}_{\mathrm{s1}}$ is the scorch time (min).

\subsubsection{Aging resistance}

The aging resistance of NR vulcanizates at high temperatures was quantified in terms of the percentage of reversion in rubber vulcanizates after 300 s from maximum torque value $\left(R_{300}\right)$. The percentage of reversion was comparatively calculated according to the equations given by Khang and Ariff and $\mathrm{Kok}^{[17,18]}$ which was expressed as follows:

$$
R_{300}=\frac{M_{H}-M_{300 s}}{M_{H}} \times 100
$$

where $\mathrm{M}_{\mathrm{H}}$ is the maximum torque in rheometric test and $\mathrm{M}_{300 \mathrm{~s}}$ is the torque 300 seconds after the maximum torque peak ${ }^{[17]}$.

$$
R_{300}=\frac{\left(T_{\max }-T_{t}\right)}{\left(T_{\max }-T_{\min }\right)} \times 100
$$

Here, $\mathrm{T}_{\max }$ is maximum torque, $\mathrm{T}_{\mathrm{t}}$ is torque at $\mathrm{t}$ seconds after maximum and $\mathrm{T}_{\min }$ is minimum torque ${ }^{[18]}$.

\subsubsection{Temperature Scanning Stress Relaxation (TSSR) Measurement}

The TSSR measurement (Brabender, Duisburg, Germany) was performed in order to investigate thermo-mechanical behavior of the NR vulcanizates ${ }^{[19]}$. The NR specimens were placed in the electrical heating chamber at temperature of about $23^{\circ} \mathrm{C}$ and at the strain of $50 \%$ for $2 \mathrm{~h}$. Non-isothermal test was then performed with heating rate of $2 \mathrm{~K} / \mathrm{min}$ until the specimens were ruptured.

Table 1. Compound formulations of NR with two alternative sulfur crosslinking systems.

\begin{tabular}{lccc}
\hline \multirow{2}{*}{ Chemical } & \multicolumn{2}{c}{ Quantity (phr) } & $\begin{array}{c}\text { Time at which } \\
\text { chemical was } \\
\text { added (min) }\end{array}$ \\
\cline { 2 - 4 } & $\mathbf{C V}$ & $\mathbf{E V}$ & 0 \\
\hline NR (STR 5L) & 100 & 100 & 2 \\
Stearic acid & 1 & 1 & \\
ZnO & 3 & 3 & 3 \\
CBS & 0.5 & 2.5 & 4 \\
Sulfur & 2.5 & 0.5 & Dump at 5 min \\
Total & $\mathbf{1 0 7}$ & $\mathbf{1 0 7}$ & \\
\hline
\end{tabular}


The crosslink density (v) was estimated from the initial part of the normalized force curve according to the following correlations $^{[13]}$ :

$$
\begin{aligned}
& \sigma=v \cdot R \cdot T\left(\lambda-\lambda^{-2}\right) \\
& v=\frac{\kappa}{R\left(\lambda-\lambda^{-2}\right)} ; \kappa=\sigma / T
\end{aligned}
$$

where, $\mathrm{R}$ is the universal gas constant, $\lambda$ is the strain ratio, $\sigma$ is mechanical stress and $\mathrm{T}$ is absolute temperature.

\subsubsection{Thermal properties}

Thermal properties of the crosslinked NR were investigated from thermogravimetric analysis with TGA4000 (PerkinElmer, USA). The samples were tested from 30 to $500{ }^{\circ} \mathrm{C}$ with a heating rate of $10{ }^{\circ} \mathrm{C} / \mathrm{min}$ and $\mathrm{N}_{2}$ flushing at $30 \mathrm{ml} / \mathrm{min}$. The degradation kinetics of crosslinked NR was also determined from thermogravimetric analysis with TGA4000 (PerkinElmer, USA) done at the heating rates of $5{ }^{\circ} \mathrm{C} / \mathrm{min}, 10{ }^{\circ} \mathrm{C} / \mathrm{min}$ and $20{ }^{\circ} \mathrm{C} / \mathrm{min}$. The formula of Flynn-Wall Ozawa (FWO) was applied to estimate the activation energy $\left(\mathrm{E}_{\mathrm{a}}\right)$ of degradation as follows ${ }^{[20,21]}$ :

$$
\operatorname{Ln}(\beta)=\left[\operatorname{Ln}\left(\frac{E_{a}}{R}\right)-\operatorname{Ln}(g(\alpha))-2.315\right]-\frac{0.4567 E_{a}}{R T}
$$

Here, $\beta$ is the heating rate, $\mathrm{E}_{\mathrm{a}}$ is the activation energy, $\mathrm{R}$ is the universal gas constant $\left(8.314 \mathrm{j} \cdot \mathrm{mol}^{-1} \cdot \mathrm{K}^{-1}\right), \mathrm{g}(\alpha)$ is a degree of conversion and $\mathrm{T}$ is the absolute temperature. By plotting the $\operatorname{Ln}(\beta)$ against $1 / \mathrm{T}$, the value of $\mathrm{E}$ can be evaluated from the slope $-0.4567 \mathrm{E}_{\mathrm{a}} / \mathrm{R}$.

\section{Results and Discussions}

\subsection{Torque-time curves of mixing}

Mixing torque profiles of the NR compounds were recorded in order to investigate changes in their molecular weights. Figure 1 shows time profiles of torque during mixing. In all cases the first peak comes from introduction of NR into the mixer. The sudden drops of torque after 2 to $3 \mathrm{~min}$ was due to ram opening to add activator and curing agents. The torque at the end of mixing was almost constant, and it is widely accepted that for polymer mixes the final torque in an internal mixer relates to the weight-average molecular weight as follows ${ }^{[22,23]}$.

$$
\text { Torque }=C \cdot N^{n} \cdot \eta_{0}
$$

and

$$
\eta_{0}=B(T) \cdot M_{w}^{3.4}
$$

Here $\mathrm{C}$ and $\mathrm{N}$ are a factor related to the geometry and the rotor speed, respectively. $M_{w}$ is the weight-averaged molecular weight, $\eta_{0}$ is the zero-shear viscosity, $B(T)$ is a temperature dependent factor, and $\mathrm{n}$ is determined from:

$$
\tau=K \gamma^{n}
$$

where $\mathrm{K}$ is the consistency index, $\tau$ refers to the shear stress and $\gamma$ is the rate of strain. Since the final mixing torques were almost identical across the cases, it is reasonable to assume that the differences in weight-average molecular weights were negligible.

\subsection{Curing characteristics}

Rheometer curves for NR crosslinked with $\mathrm{CV}$ and $\mathrm{EV}$ systems are shown in Figure 2. It can be seen that the curves show differently. As for the EV system, the torque increased steeply with vulcanization time until reaching its maximum, after which it remained constant (plateau). This is not similar to $\mathrm{CV}$ system where the torque decreased (reversion) after its maximum. This pattern of behaviour is frequently found when NR is crosslinked with CV and EV systems ${ }^{[24]}$. It has been reported that the majority crosslink formation in the CV systems was poly and disulfidics ( $>90 \%)$, while the monosulfidic was dominant in the EV system $(>80 \%)^{[25]}$. The plateau behaviour with EV system is thus due to thermally stable crosslinks of monosulfidic types, while decreasing torque after the maximum with the CV system is attributed to breakdown of some thermally unstable polysulfidic crosslinks with lesser bond strength $(<262 \mathrm{~kJ} / \mathrm{mol})$ than

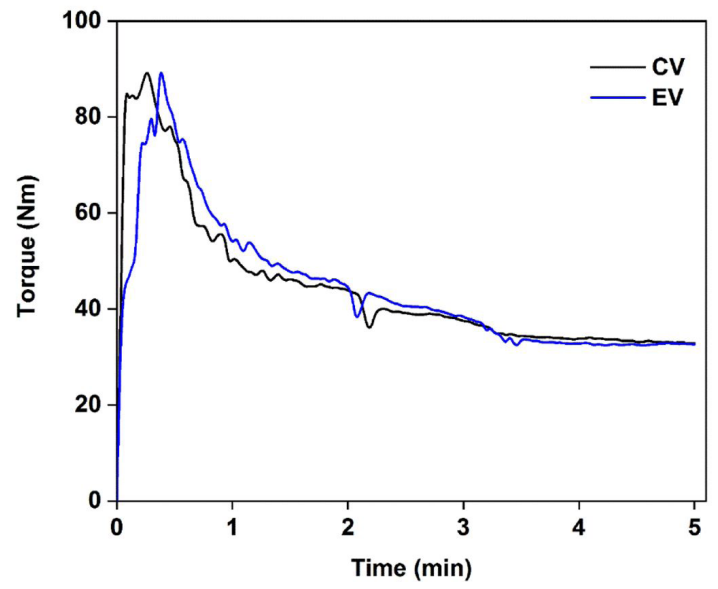

Figure 1. Torque-time curves during mixing the NR compounds.

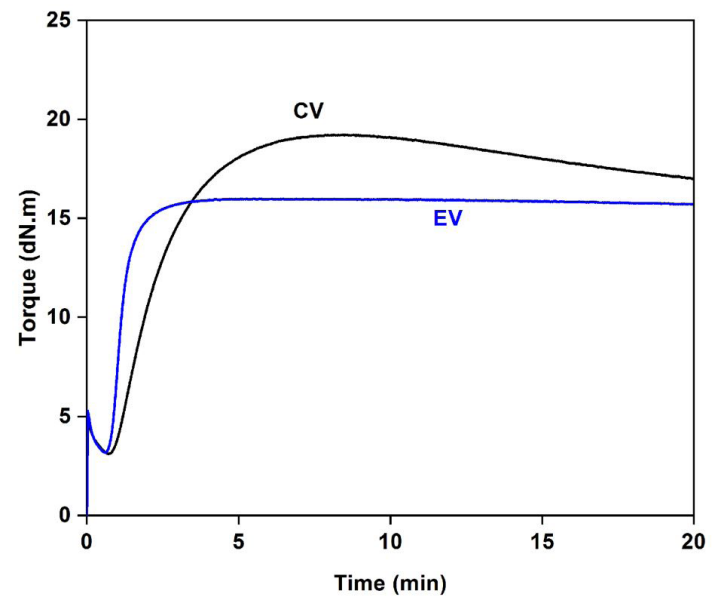

Figure 2. Rheometeric curves for NR crosslinked with $\mathrm{CV}$ and EV systems. 
the monosulfidic linkages $(\sim 280 \mathrm{~kJ} / \mathrm{mol})^{[8,9]}$. The curing parameters in term of maximum torque $\left(\mathrm{M}_{\mathrm{H}}\right)$ and torque difference $\left(\mathrm{M}_{\mathrm{H}}-\mathrm{M}_{\mathrm{L}}\right)$ obtained with the $\mathrm{CV}$ and $\mathrm{EV}$ systems are shown in Table 2 . The $\mathrm{T}_{\mathrm{sl}}$ and $\mathrm{T}_{\mathrm{c} 90}$ were shorter with $\mathrm{EV}$ than with CV systems, indicating that the EV system had shorter scorch safety and vulcanization times. As a result of fast curing, the CRI value of EV system is higher than that of the CV system. This was probably resulted from high dosages of accelerator to sulfur. Furthermore, the $\mathrm{M}_{\mathrm{H}}$ and $M_{H}-M_{L}$ values were much higher with $C V$ than with $E V$ systems. The higher value of the $\mathrm{M}_{\mathrm{H}}$ indicates the higher stiffness of the CV sample after fully vulcanization, while the greater $M_{H}-M_{L}$ is the higher the crosslink density ${ }^{[26]}$. The higher stiffness and crosslink density with CV system is due to the higher concentration of sulfur for initiating crosslink reactions than in the EV system. As a result, more extensive vulcanization takes place with the CV system.

\subsection{Reversion resistance}

Reversion resistance of NR crosslinked with $\mathrm{CV}$ and $\mathrm{EV}$ systems was investigated by exposure to shear and elevated temperature for a certain period of time. Figure 3 displays the percentage of reversion according to the equations given by Khang and Ariff ${ }^{[17]}$ and Kok $^{[18]}$.

As the percentage of reversion was estimated after a certain time past the maximum torque, a greater value means higher reversion. A larger value $\mathrm{R}_{300}$ was detected for the CV system, meaning that the NR crosslinked with $\mathrm{CV}$ system had poorer reversion resistance as compared with the EV system. As previously mentioned, polysulfidic linkages are dominant with the $\mathrm{CV}$ system but monosulfidic linkages are dominant with the EV system. The polysulfidic linkages have poorer bond strength $\left(<265 \mathrm{~kJ} \mathrm{~mol}^{-1}\right)^{[8,9]}$, and were easier to break by shear and heat.

\subsection{Temperature scanning stress relaxation (TSSR)}

Figure 4 shows normalized force curves of the samples crosslinked with $\mathrm{CV}$ and $\mathrm{EV}$ systems as a function of temperature. The embedded figure was a magnifying of the initial curves in the temperature range of 30 to $40^{\circ} \mathrm{C}$. It is generally seen from Figure 4 that the initial normalized force of both samples increased slightly at temperatures of $30-40{ }^{\circ} \mathrm{C}$ due to the entropy effect ${ }^{[27]}$ and the increase of force was sharper in the CV system (see embedded figure), implying the higher crosslink density of the $\mathrm{CV}$ sample. The crosslink density of the $\mathrm{CV}$ and $\mathrm{EV}$ systems was about 111.25 and $87.32 \mathrm{~mol} / \mathrm{m}^{3}$. At elevated temperature, the force decrease toward zero due to chain scission caused by thermo-oxidative reaction occurs ${ }^{[19]}$. It is also seen that the force at any given temperature of the EV system was shifted to higher temperature, compared to the CV system. In some cases, the shift of these parameters was attributed to the molecular weight difference ${ }^{[16]}$ and crosslink densities ${ }^{[8,10]}$, but these two reasons were not applicable for this study due to the negligible change in molecular weight(see Figure 1) and a higher crosslink was gained from the CV system. Thus, influence of crosslink degree and molecular weight can be eliminated. As previously mentioned, the EV system contains majority high thermal stability monosulfidic linkages while the less thermal stability polysulfidic linkages are dominant in the $\mathrm{CV}$ system. Thus,
Table 2. Curing properties in terms of $\mathrm{T}_{\mathrm{s1}}, \mathrm{T}_{\mathrm{c} 90^{\circ}}, \mathrm{CRI}, \mathrm{M}_{\mathrm{H}}$ and $\mathrm{M}_{\mathrm{H}}-\mathrm{M}_{\mathrm{L}}$ for NR crosslinked with $\mathrm{CV}$ and $\mathrm{EV}$ systems.

\begin{tabular}{ccc}
\hline \multirow{2}{*}{ Cure characteristic } & \multicolumn{2}{c}{ Curing system } \\
\cline { 2 - 3 } & CV & EV \\
\hline $\mathrm{T}_{\mathrm{s} 1}(\mathrm{~min})$ & $1.17 \pm 0.05$ & $0.89 \pm 0.00$ \\
$\mathrm{~T}_{\mathrm{c} 90}(\mathrm{~min})$ & $4.38 \pm 0.22$ & $1.95 \pm 0.09$ \\
$\mathrm{CRI}\left(\mathrm{min}^{-1}\right)$ & $31.20 \pm 1.65$ & $95.15 \pm 8.29$ \\
$\mathrm{M}_{\mathrm{H}}(\mathrm{dN} . \mathrm{m})$ & $18.88 \pm 0.48$ & $16.10 \pm 0.15$ \\
$\mathrm{M}_{\mathrm{H}}-\mathrm{M}_{\mathrm{L}}(\mathrm{dN} . \mathrm{m})$ & $15.81 \pm 0.44$ & $12.93 \pm 0.16$ \\
\hline
\end{tabular}
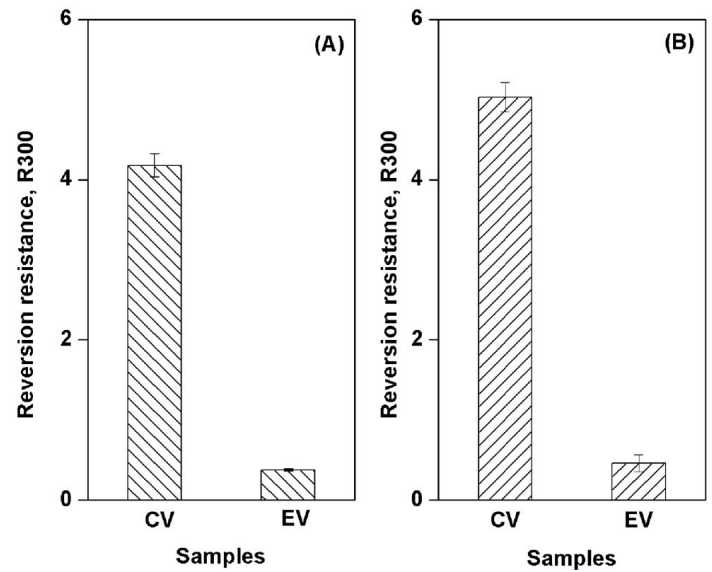

Figure 3. Reversion resistances $\left(\mathrm{R}_{300}\right)$ of $\mathrm{NR}$ crosslinked with $\mathrm{CV}$ and EV systems calculated according to (A) Ref 17, and (B) Ref 18.

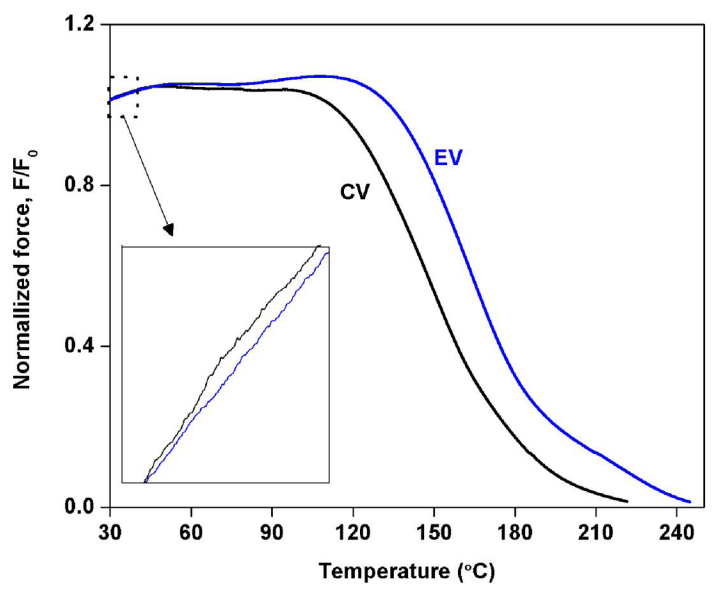

Figure 4. Normalized force curves of NR crosslinked with CV and EV systems.

it is reasonable to conclude that the lower thermo-oxidative degradation level in the EV system was attributed to the higher thermal stability of monosulfidic linkages. The result clearly confirmed that the type of crosslinks is the main parameter controlling thermal behaviour of the rubber vulcanizates.

The TSSR relaxation spectra of various samples are shown in Figure 5. In the unfilled vulcanizates, the relaxation peak was usually caused by cleavage of sulfur bridges and/or scission of the polymer main chain ${ }^{[14]}$. It is seen that the peak of relaxation spectrum of EV system was shifted toward higher temperature, revealing that the breakage of sulfur bridges and/or chain scission of the main chains occur 


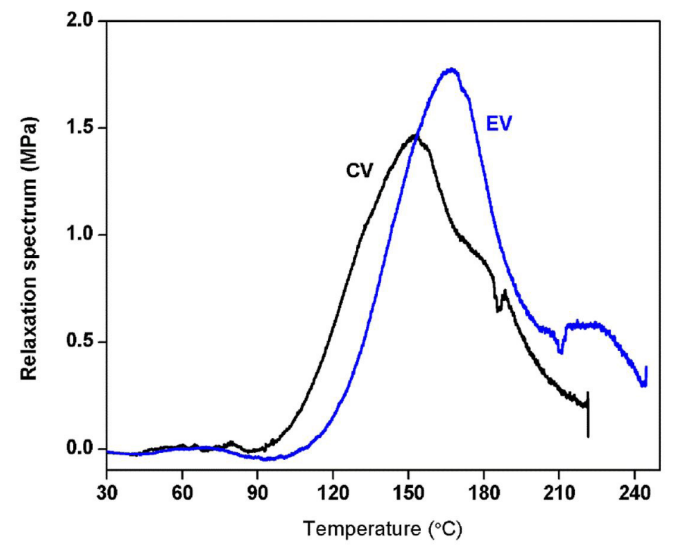

Figure 5. Relaxation spectrum of NR crosslinked with $\mathrm{CV}$ and EV systems.
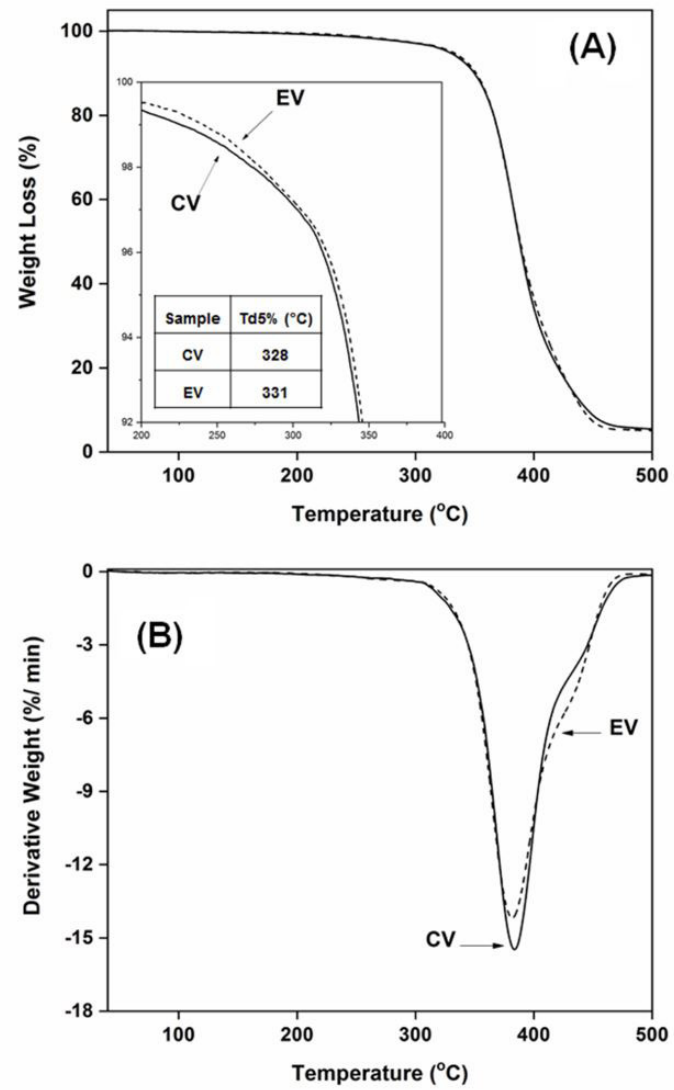

Figure 6. Thermogravimetric curves: (A) weight loss (\%), and (B) derivative weight loss versus temperature of NR samples at $10{ }^{\circ} \mathrm{C} / \mathrm{min}$ heating rate.

at higher temperature as compared to the CV system. This was attributed to the fact that the higher thermal stability of monosulfidic linkages formed with the EV system ${ }^{[8,9]}$. As a result of stronger bonding energy of monosulfidic linkage, the stress relaxation behaviour of the EV system was found at higher temperature than the CV system. Therefore, the aging resistance of the $\mathrm{CV}$ was poorer than that of the $\mathrm{EV}$ system can be confirmed.
It is widely accepted that within temperature range of TSSR measurement, the changes in mechanical properties due to crosslink scission of the rubber structures can be detected. But at higher temperature, crosslink scission and main chain degradation occur simultaneously. To further understand the degradation of CV and EV systems at high temperature and to correlate high temperature properties with low temperature behaviors, TGA was performed.

\subsection{Thermal properties}

TGA analysis was performed in order to observe thermal degradation behavior and thermal stability for NR crosslinked with CV and EV systems. In this study, the thermal stability of the NR vulcanizates was evaluated from that temperature at which the sample had lost $5 \%$ of its initial weight $\left(\mathrm{T}_{\mathrm{d} 5}\right)$. The relationship of weight loss (\%) with temperature and the derivative weight loss curves at heating rate of $10^{\circ} \mathrm{C} / \mathrm{min}$ are shown in Figure $6 \mathrm{~B}$. It is seen from Figure 6Athat the crosslinked NR samples showed two regions of degradation: a minor weight loss at $180-300{ }^{\circ} \mathrm{C}$, and a major loss at $300-470{ }^{\circ} \mathrm{C}$. The former weight loss was attributed to volatile substances including stearic acid and moisture, and the latter was due to the degradation of rubber molecules ${ }^{[28]}$. The $\mathrm{T}_{\mathrm{d} 5}$ with the $\mathrm{CV}$ system appeared at $328^{\circ} \mathrm{C}$, which is lower than the corresponding temperature with the EV system $\left(331^{\circ} \mathrm{C}\right)$, meaning that the $\mathrm{CV}$ system gave poorer thermal stability than the EV system.

Considering the derivative weight loss curves (Figure 6B), the maximum degradation rate with the EV system $(-14.19 \mathrm{wt} \% / \mathrm{min})$ was slower than with the CV system (-15.47 wt \%/min). The degradation of NR chains crosslinked with the EV system was slightly harder than with the CV system. Again, this was attributed to the higher thermal stability of linkages formed with the EV system. As the CV system provided higher crosslinking degree but the thermal properties with CV were poorer than with the EV system. Therefore, the degree of crosslinking does not determine the thermal stability (or resistance to degradation). Only type of crosslinkage is responsible for this change. Higher thermal stability of monosulfidic linkage formed with the EV system may retard both the scission of crosslink and degradation of main chain. The TGA results are in accordance well with the TSSR result as previously shown.

To gain further confirm the degradation process of NR crosslinked with CV and EV systems, activation energies associated with degradation was estimated. The activation energy is the minimum energy required of molecules for them to undergo a phase transition during heating ${ }^{[29]}$. Plots of $\operatorname{Ln}(\beta)$ versus $1 / \mathrm{T}$ for NR crosslinked with the two alternative systems are shown in Figure 7, and the estimates of activation energies are shown in Figure 8. The degradation after curing with the $\mathrm{CV}$ system required a lesser activation energy than with the EV system, so the former case was easier to degrade. The higher activation energy with the EV system clearly confirms that the NR crosslinked with EV system had harder degradation and better thermal stability than with the CV system. This is here tentatively attributed to the crosslink system.

Since the high temperature results obtained from TGA measurement agreed well with the low temperature behavior 

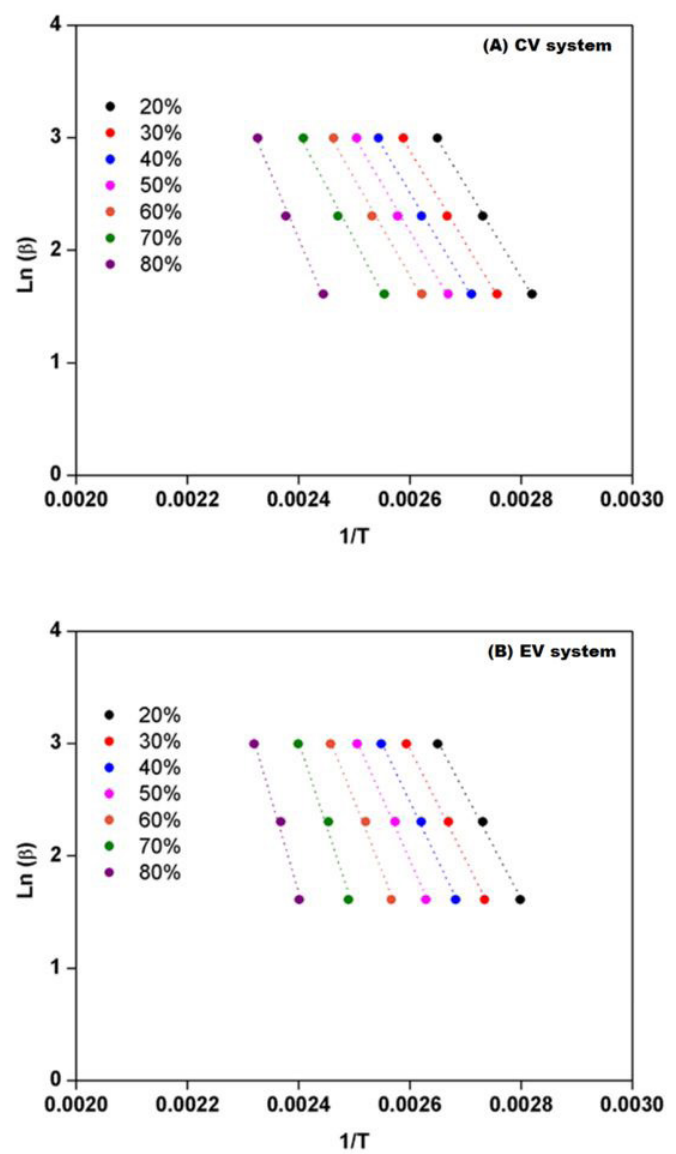

Figure 7. Plot of $\operatorname{Ln}(\beta)$ versus $1 / \mathrm{T}$ for NR crosslinked with (A) CV, and (B) EV systems.

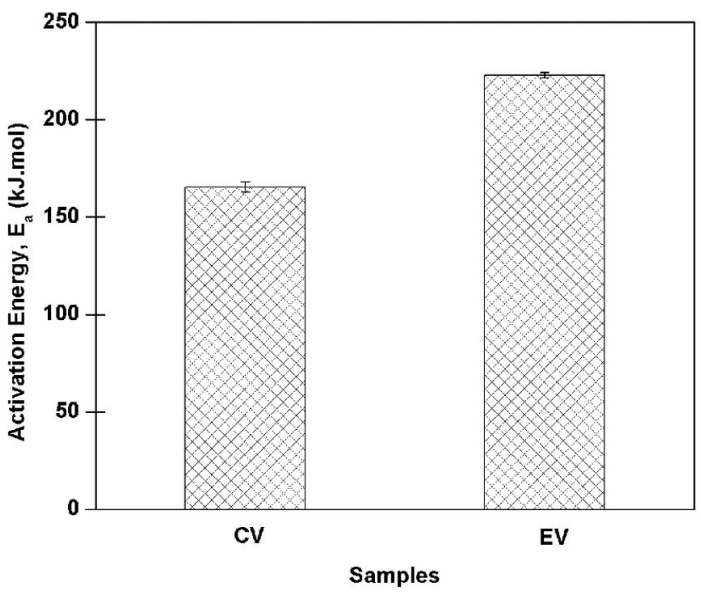

Figure 8. Activation energy of thermal degradation for NR crosslinked with $\mathrm{CV}$, and $\mathrm{EV}$ systems.

tested by TSSR technique, it is reasonable to assume that the thermal behavior at higher temperature can be partially estimated by using temperature stress relaxation technique which was tested at lower temperature.

\section{Conclusions}

In this study, influences of two alternative sulfur vulcanization systems, of CV and EV types, on curing reaction, stress relaxation behavior and thermal properties of $\mathrm{NR}$ vulcanizates were investigated. The $\mathrm{CV}$ system provided higher maximum toque and torque different. From TSSR measurements, the degree of crosslinking was greater with the $\mathrm{CV}$ system. However, higher crosslink and chain scissions caused by thermo-oxidative occurs in the CV system due to the polysulfidic crosslinks having comparatively poorer thermal stability. The monosulfidic linkage in the EV system tentatively provided better resistance to the scission of both crosslink and rubber chains as revealed by TGA analysis. The degradation of the rubber main chain was found to hinder by the EV system as was later confirmed by higher activation energy. Both TSSR measurement and TGA analysis showed well agreement that the better aging property, thermo-oxidative resistance and thermal stability were greater with the EV system.

\section{Acknowledgements}

The authors gratefully acknowledged Prince of Songkla University for financial support (Grant no. RDO6202102S). Research and Development Office (RDO) of Prince of Songkla University and Assoc. Prof. Dr. Seppo Karrila are also acknowledged for assistance in editing the English language in this manuscript.

\section{References}

1. Coran, A. Y. (2013). Vulcanization. In B. Erman, J. E. Mark, \& C. M. Roland (Eds.), The science and technology of rubber (pp. 337-381). Amsterdam: Elsevier. http://dx.doi.org/10.1016/ B978-0-12-394584-6.00007-8.

2. Khan, I., \& Bhat, A. H. (2014). Micro and nano calcium carbonate filled natural rubber composites and nanocomposites. In S. Thomas, C. H. Chan, L. Pothen, J. Joy, \& H. Maria (Eds.), Natural rubber materials, vol 2: Composites and nanocomposites (pp. 467-487). Cambridge: Royal Society of Chemistry.

3. Coran, A. Y. (1995). Vulcanization: Conventional and dynamic. Rubber Chemistry and Technology, 68(3), 351-375. http:// dx.doi.org/10.5254/1.3538748.

4. Hoover, F. I., \& To, B. H. (2004). Vulcanization. In B. Rodgers (Ed.), Rubber compounding: Chemistry and applications (pp. 505-568). New York: Marcel Dekker Inc.

5. Ciullo, P. A., \& Hewitt, N. (1999). The rubber formulary. New York: William Andrew.

6. Datta, R. N. (2002). Rubber curing systems. Shawbury: Smithers Rapra Technology.

7. Linhares, F. N., Kersch, M., Niebergall, U., Moreira Leite, M. C. A., Atlstadt, V., \& Furtado, C. R. G. (2017). Effect of different sulphur-based crosslink networks on the nitrile rubber resistance to biodiesel. Fuel, 191, 130-139. http:// dx.doi.org/10.1016/j.fuel.2016.11.060.

8. Pimolsiriphol, V., Saeoui, P., \& Sirisinha, C. (2007). Relationship among thermal ageing degradation, dynamic properties, cure systems, and antioxidants in natural rubber. Polymer-Plastics Technology and Engineering, 46(2), 113-121. http://dx.doi. org/10.1080/03602550601152861.

9. Bhowmick, A. K., \& Mangaraj, D. (1994). Vulcanization and curing techniques. In A. K. Bhowmick, M. M. Hall, \& H. A. 
Benarey (Eds.), Rubber products manufacturing technology (pp. 315-396). New York: Marcel Dekker Inc.

10. Larpkasemsuk, A., Raksaksri, L., Chuayjuljit, S., Chaiwuthinan, P., \& Boonmahidthisud, A. (2019). Effects of sulfur vulcanization system on cure characteristics, physical properties and thermal aging of epoxidized natural rubber. Journal of Metals Materials and Minerals, 29(1), 49-57.

11. Boonkerd, K., Deeprasertkul, C., \& Boonsomwong, K. (2016). Effect of sulfur to accelerator ratio on crosslink structure reversion, and strength in natural rubber. Rubber Chemistry and Technology, 89(3), 450-464. http://dx.doi.org/10.5254/ ret.16.85963.

12. Rattanasom, N., Poonsuk, A., \& Makmoon, T. (2005). Effect of curing system on the mechanical properties and heat aging resistance of natural rubber/tire tread reclaimed rubber blends. Polymer Testing, 24(6), 728-732. http://dx.doi.org/10.1016/j. polymertesting.2005.04.008.

13. Vennemann, N., Bokamp, K., \& Broker, D. (2006). Crosslink density of peroxide cured TPV. Macromolecular Symposia, 245 246(1), 641-650. http://dx.doi.org/10.1002/masy.200651391.

14. Vennemann, N., Schwarze, C., \& Kummerlowe, C. (2014). Determination of crosslink density and network structure of NR Vulcanizates by means of TSSR. Advanced Materials Research, 844, 482-485. http://dx.doi.org/10.4028/www. scientific.net/AMR.844.482.

15. Oncel, S., Kurtoglu, B., \& Karaagac, B. (2019). An alternative antioxidant for sulfur-vulcanized natural rubber: henna. Journal of Elastomers and Plastics, 51(5), 440-456. http://dx.doi. org/10.1177/0095244318796594.

16. Karaagac, B., Cengiz, S. C., Bayram, T., \& Sen, M. (2018). Identification of temperature scanning stress relaxation behaviors of new grade ethylene propylene diene elastomers. Advances in Polymer Technology, 37(8), 3027-3037. http:// dx.doi.org/10.1002/adv.21973.

17. Khang, T. H., \& Ariff, Z. M. (2012). Vulcanization kinetics study of natural rubber compounds having different formulation variables. Journal of Thermal Analysis and Calorimetry, 109(3), 1545-1553. http://dx.doi.org/10.1007/s10973-011-1937-3.

18. Kok, C. M. (1987). The effects of compounding variables on the reversion process in the sulphur vulcanization of natural rubber. European Polymer Journal, 23(8), 611-615. http:// dx.doi.org/10.1016/0014-3057(87)90006-1.

19. Srinivasan, N., Bokamp, K., \& Vennemann, N. (2005). New test method for the characterisation of filled elastomers. $K G K$. Kautschuk, Gummi, Kunststoffe, 2005(58), 650.

20. Alwaan, I. M., \& Hassan, A. (2014). Pyrolysis, kinetic and kinetic model study of epoxidized natural rubber. Progress in
Rubber, Plastics and Recycling Technology, 30(3), 153-168. http://dx.doi.org/10.1177/147776061403000303.

21. Chrissafis, K. (2009). Kinetics of thermal degradation of polymer, complementary use of isoconversional and modelfitting methods. Journal of Thermal Analysis and Calorimetry, 95(1), 273-283. http://dx.doi.org/10.1007/s10973-008-9041-z.

22. Jung, C., Jana, S. C., \& Gunes, I. S. (2007). Analysis of polymerization in chaotic mixers using time scales of mixing and chemical reactions. Industrial \& Engineering Chemistry, 46(8), 2413-2422. http://dx.doi.org/10.1021/ie0613319.

23. Verhoeven, V. W. A., van Vondel, M. P. Y., Ganzeveld, K. J., \& Janssen, L. P. B. M. (2004). Rheo-kinetic measurement of thermoplastic polyurethane polymerization in a measurement kneader. Polymer Engineering and Science, 44(9), 1648-1655. http://dx.doi.org/10.1002/pen.20163.

24. Rabiei, S., \& Shojaei, A. (2016). Vulcanization kinetics and reversion behavior of natural rubber/styrene-butadiene rubber blend filled with nanodiamond - The role of sulfur curing system. European Polymer Journal, 81, 98-113. http://dx.doi. org/10.1016/j.eurpolymj.2016.05.021.

25. Akiba, M., \& Hashim, A. S. (1997). Vulcanization and crosslinking in elastomer. Progress in Polymer Science, 22(3), 475-521. http://dx.doi.org/10.1016/S0079-6700(96)00015-9.

26. Surya, I., \& Ismail, H. (2016). Alkanolamide as a novel accelerator and vulcanising agent in carbon black-filled polychloroprene rubber compounds. Plastics, Rubber and Composites, 45(7), 287-293. http://dx.doi.org/10.1080/14658011.2016.1187477.

27. Barbe, A., Bokamp, K., Kummerlowe, C., Sollmann, H., Vennemann, N., \& Vinzelberg, S. (2005). Investigation of modified SEBS-based thermoplastic elastomers by temperature scanning stress relaxation measurements. Polymer Engineering and Science, 45(11), 1498-1507. http://dx.doi.org/10.1002/ pen. 20427.

28. Hayeemasae, N., Ismail, H., Matchawet, S., \& Masa, A. (2019). Kinetic of thermal degradation and thermal stability of natural rubber filled with titanium dioxide nanoparticles. Polymer Composites, 40(8), 3149-3155. http://dx.doi.org/10.1002/ pc. 25163 .

29. Tripathy, S. P., Mishra, R., Fink, D., \& Dwivedi, K. K. (2004). Irradiation effect on the activation energy of thermal decomposition of polymers. Radiation Effects and Defects in Solids, 159(11-12), 607-612. http://dx.doi.org/10.1080/1042 0150412331330502 .

Received: Mar. 16, 2020

Revised: June 17, 2020

Accepted: June 18, 2020 